\title{
Laminar Natural Convection Over a Slender Vertical Frustrum of a Cone with Constant Wall Heat Flux
}

\author{
T. Y. Na, Dearborn and J. P. Chiou, Detroit
}

\begin{abstract}
The problem of laminar natural convection flow over a slender frustrum of a cone with constant wall heat flux is treated in this paper. The governing differential equations are solved by a combination of quasilinearization and finite-difference methods. Numerical solutions are obtained for Prandtl numbers from 0.1 to 100 for a range of values of transverse curvature parameter. It is found that the effect of transverse curvature is of great significance in such flows.
\end{abstract}

Laminare natürliche Konvektion über einem dünnen, senkrechten Kegelstumpf mit konstantem Wandwärmestrom

Zusammenfassung. In dieser Arbeit wird das Problem der laminaren, natürlichen Konvektionsströmung über einem dünnen Kegelstumpf mit konstantem Wandwärmestrom behandelt. Die maßgeblichen Differentialgleichungen werden mit Hilfe einer Kombination von Quasilinearisierung und Differenzenverfahren gelöst. Numerische Lösungen werden für die Prandtl' schen Zahlen zwischen 0.1 und 100 innerhalb eines Bereiches von Querkrüm mungswerten erhalten. Es wird gezeigt, daß der Einfluß der Querkrümmung in solchen Strömungen von großer Bedeutung ist.

\section{Nomenclature}

$A, B, C$ constants in the transformation, defined in

Eq. (14)

f dependent variable, defined in Eq. (7)

$\mathrm{g}$ dependent variable, defined in Eq. (7)

$\mathrm{g}_{e} \quad$ gravitational acceleration

k. heat conductivity

$\mathrm{k}_{n} \quad$ s-grid

L characteristic length

$\mathrm{Nu} \quad$ Nusselt number

Pr Prandtl number

$\mathrm{q}_{\mathrm{w}} \quad$ wall heat flux

$r$ radial distance from the axis of the cone

$R_{\text {TVC }}$ transverse curvature ratio, defined in $\mathrm{Eq} \cdot(28)$

\section{$\underline{\text { Introduction }}$}

The problem of laminar natural convection flow over a vertical cone has been treated in the literature by many authors since 1953. Merk and Prins [1] found the similarity solution for the case of an isothermal cone. The case was extended by Hering and Grosh [2] to the case of non-isothermal cones where the wall temperature varies as $x^{n}$. Similarity solutions were obtained for a family of values of the $n$ 's. Further analyses of this problem for low Prandtl numbers were made by Hering [3] and Sparrow and Guinle [4] and, for large Prandtl numbers, by Roy [5]. Other

\begin{tabular}{|c|c|}
\hline $\begin{array}{l}\mathrm{Re} \\
\mathrm{T}\end{array}$ & Reynolds number. \\
\hline $\mathrm{u}, \mathrm{v}$ & $\begin{array}{l}\text { velocity components in the } \mathrm{x}-\text { and } \mathrm{y} \text {-direc- } \\
\text { tions, respectively }\end{array}$ \\
\hline $\mathrm{x}, \mathrm{y}$ & rectangular coordinates \\
\hline \multicolumn{2}{|c|}{ Greek Letters } \\
\hline$\theta$ & $\begin{array}{l}\text { dimensionless temperature, defined in } \\
\mathrm{Eq.} \text { (4) }\end{array}$ \\
\hline$\beta$ & bulk modulus \\
\hline$\alpha$ & cone angle \\
\hline$\nu$ & dynamic viscosity \\
\hline$\psi$ & stream function \\
\hline$\xi, \eta$ & $\begin{array}{l}\text { transformed independent variables, defined } \\
\text { in Eq. (7) }\end{array}$ \\
\hline & ansverse curvature parameter \\
\hline
\end{tabular}

analyses include the solutions for cones with a constant-wall-heat flux boundary condition [6], for slender cones with power-law wall temperature [7] and for a slender frustrum of a cone with constant wall temperature [8]. In all these works with the exception of references [7] and [8], the cone angles under consideration were large so that the effect of transverse curvature was negligible. From the mathematical point of view, such flows were similar and, as such, the governing differential equations can be reduced to ordinary differential equations.

When the cone angle is small, the boundary layer thickness is of the same order-of-magnitude of the 

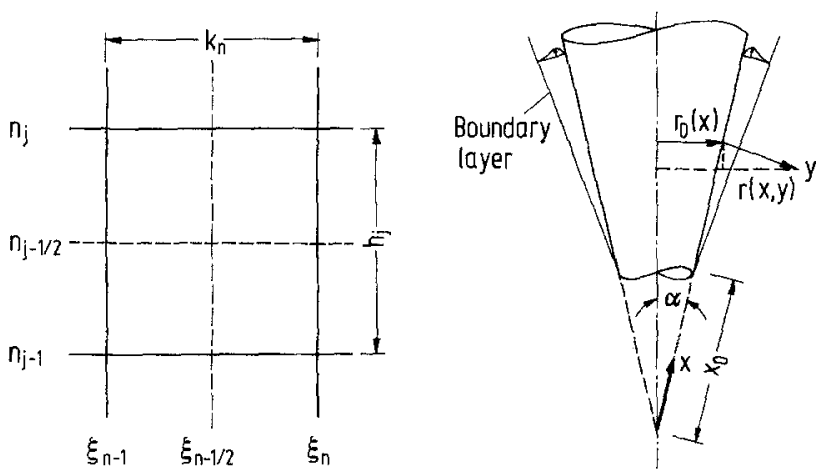

Fig. 1. The coordinate system

cone $[7-10]$ so that the transverse curvature terms have to be retained in the governing differential equations. The result is that the differential equations are non-similar, which means the differential equations are no longer reducible to ordinary differential equations.

In this paper, the problem of natural convection flow over a frustrum of a cone will betreated for the case of specified wall heat flux. Similar to reference $[8]$, the governing differential equations are first linearized by the quasilinearization method. The resulting equations are then solved by a finite-difference method outlined in detail in reference 11. Referring to Figure 1, the flow over a frustrum of a cone will approach to the flow over a full cone as $x_{0}$ approaches to zero. It should be pointed out that the differential equations in this analysis will be reduced to the similarity equations of Lin [6] if the transverse curvature terms are omitted.

\section{Analysis}

The governing differential equations for the solution of natural convection flow past a slender vertical frustrum of a cone with constant wall heat fluxes (Fig.1) can be written in terms of dimensionless quantities as:

$$
\begin{aligned}
& \frac{\partial(\overline{\mathrm{r}} \overline{\mathrm{u}})}{\partial \overline{\mathrm{x}}}+\frac{\partial(\overline{\mathrm{r}} \overline{\mathrm{v}})}{\partial \overline{\mathrm{y}}}=0 \\
& \overline{\mathrm{u}} \frac{\partial \overline{\mathrm{u}}}{\partial \overline{\mathrm{x}}}+\overline{\mathrm{v}} \frac{\partial \overline{\mathrm{u}}}{\partial \overline{\mathrm{y}}}=\frac{1}{\overline{\mathrm{r}}} \frac{\partial}{\partial \overline{\mathrm{y}}}\left\{\overline{\mathrm{r}} \frac{\partial \overline{\mathrm{u}}}{\partial \overline{\mathrm{y}}}\right\}+\theta \\
& \overline{\mathrm{u}} \frac{\partial \theta}{\partial \overline{\mathrm{x}}}+\overline{\mathrm{v}} \frac{\partial \theta}{\partial \overline{\mathrm{y}}}=\frac{1}{\operatorname{Pr}} \frac{1}{\overline{\mathrm{r}}} \frac{\partial}{\partial \overline{\mathrm{y}}}\left\{\overline{\mathrm{r}} \frac{\partial \theta}{\partial \overline{\mathrm{y}}}\right\} .
\end{aligned}
$$

The boundary conditions are:

$\overline{\mathrm{y}}=0: \overline{\mathrm{u}}=0 ; \overline{\mathrm{v}}=0 ; \frac{\partial \theta}{\partial \overline{\mathrm{y}}}=-1$

$\bar{y}=\alpha: \bar{u}=0 ; \theta=0$.

The dimensionless quantities in Eqs. (1-3) are related to their corresponding physical variables through the following definitions:

$$
\begin{aligned}
& \bar{x}=\frac{x-x_{0}}{L} ; \bar{y}=\frac{y}{L} \sqrt{R e_{L}} ; \bar{u}=\frac{u}{u_{c}} ; \bar{v}=\frac{v}{u_{c}} \sqrt{R e_{L}} \\
& \bar{r}_{0}=\frac{r_{0}(x)}{L} \sqrt{R e_{L}} ; \theta=\frac{T-T_{\propto}}{\left(\frac{q_{0} L}{k \sqrt{R e_{L}}}\right)} ; \bar{r}=\frac{r}{L} \sqrt{R e_{L}}
\end{aligned}
$$

where

$$
\begin{aligned}
& u_{c}=\left\{g_{e} \beta \cos \alpha\left[\frac{q_{0} L}{k}\right](L \nu)^{1 / 2}\right\}^{2 / 5} \\
& \operatorname{Re}_{L}=\frac{u_{c} L}{\nu} .
\end{aligned}
$$

If the characteristic length, $\mathrm{L}$, is chosen as the distance $x_{0}$ (Fig.1), then the Reynold number becomes:

$\operatorname{Re}_{L}=\frac{u_{c} x_{0}}{\nu}=\left\{\frac{g_{e^{\beta \cos \alpha}\left(q_{0} x_{0} / k\right) x_{0}^{3}}}{\nu^{2}}\right\}^{2 / 5}=G r_{x_{0}}^{2 / 5}$

where $\mathrm{Gr}_{\mathrm{x}_{0}}$ is the Grashof number based on $\mathrm{x}_{0}$.

Next, the following transformation will be introduced :

$\xi=\bar{x} ; \quad \eta=\frac{\bar{y}}{\bar{x}^{-1 / 5}}$

$f(\xi, \eta)^{-}=\frac{y}{x^{-4 / 5} r_{0}} ; g(\xi, \eta)=\frac{\theta}{x^{-1 / 5}}$

where the stream function $\psi$ is defined by:

$\bar{r} \bar{u}=\frac{\partial \psi}{\partial \bar{y}}$ and $\bar{r} \bar{v}=-\frac{\partial \psi}{\partial \bar{x}}$

and, for cones,

$r_{0}=x \sin \alpha$. 
Equations (1-3) then become:

$$
\begin{aligned}
& \left(\frac{\overline{\mathrm{r}}_{0}}{\overline{\mathrm{r}}}\right)\left\{\left(\frac{\overline{\mathrm{r}}}{\overline{\mathrm{r}}_{0}}\right)\left[\left(\frac{\overline{\mathrm{r}}_{0}}{\overline{\bar{r}}}\right) \mathrm{f}^{\prime}\right]^{\prime}\right\}^{\prime}+ \\
& +\left(\frac{\bar{r}_{0}}{\bar{r}}\right)\left\{\left(\frac{\bar{r}_{0}}{\bar{r}}\right) f^{\prime}\right\}^{\prime}\left\{\left(R+\frac{4}{5}\right) f-\frac{1}{5} \eta f^{\prime}\right\} \\
& -\left(\frac{\overline{\mathrm{r}}_{0}}{\overline{\mathrm{r}}}\right)^{2} \mathrm{f}^{\prime}\left\{\left(\mathrm{R}+\frac{3}{5}-\mathrm{R} \frac{\overline{\mathrm{r}}_{0}}{\overline{\mathrm{r}}}\right) \mathrm{f}^{\prime}-\frac{1}{5} \eta \mathrm{f}^{\prime \prime}\right\}+\mathrm{g} \\
& =\xi\left\{\left(\frac{\bar{r}_{0}}{\bar{r}}\right)^{2} f^{\prime} \frac{\partial f^{\prime}}{\partial \xi}-\left(\frac{\bar{r}_{0}}{\bar{r}}\right)\left[\left(\frac{\bar{r}_{0}}{\bar{r}}\right) f^{\prime}\right]^{\prime} \frac{\partial f}{\partial \xi}\right\} \\
& \frac{1}{\operatorname{Pr}}\left\{\left(\frac{\bar{r}}{\bar{r}_{0}}\right) g^{\prime}\right\}^{\prime}+\left(R+\frac{4}{5}\right) f g^{\prime}-\frac{1}{5} f^{\prime} g \\
& =\xi\left(f^{\prime} \frac{\partial g}{\partial \xi}-g^{\prime} \frac{\partial f}{\partial \xi}\right)
\end{aligned}
$$

subject to the boundary conditions:

$\eta=0: f(\xi, 0)=f^{\prime}(\xi, 0)=0 ; g^{\prime}(\xi, 0)=-1$

$\eta=\propto: f^{\prime}(\xi, \propto)=0 ; g(\xi, \propto)=0$

where primes in Eqs. (9) and (10) represent differentiation with respect to $\eta$, and

$R=\frac{\bar{x}}{\bar{r}_{0}} \frac{d \bar{r}_{0}}{d \bar{x}}=\frac{\bar{x}}{1+\bar{x}}=\frac{\xi}{1+\xi}$.

The ratio $r / r_{0}$ represents the effect of transverse curvature. For flows far downstream, $r$ is very close to $r_{0}$ and the effects of the transverse curvature are negligible. Furthermore, the parameter $\mathrm{R}$ approaches to 1 when $\mathrm{x}$ becomes large. Equations (9) and (10) become similar and can be written as:

$f^{\prime \prime \prime}+\frac{9}{5} f^{\prime \prime}-\frac{3}{5}\left(f^{\prime}\right)^{2}+g=0$

$\frac{1}{\mathrm{Pr}} g^{\prime \prime}+\frac{9}{5} f g^{\prime}-\frac{1}{5} f^{\prime} g=0$

which can be reduced to the form given by Lin [6] through the transformation:
$\eta^{*}=A \eta, f^{*}=B f, \theta^{*}=C g$

and

$A=-C=\left(\frac{9}{20}\right)^{1 / 5} ; B=A^{4}$.

The starred quantities in Eq. (14) ref er to the same variables in Lin [6]'s work.

For cones, we have

$r=r_{0}+y \cos \alpha$

$r_{0}=x \sin \alpha$.

In terms of the similarity variables defined in Eq. (7), the ratio $\overline{\mathrm{r}} / \overline{\mathrm{r}}_{0}$ can therefore be written as:

$\frac{\overline{\mathbf{r}}}{\overline{\mathbf{r}}_{0}}=1+\gamma \frac{\xi^{1 / 5}}{1+\xi} \eta$

where the TVG (transverse curvature) parameter $\gamma$ is defined as:

$\gamma=\frac{\operatorname{Cot} \alpha}{\operatorname{Gr}_{\mathrm{x}_{0}}^{1 / 5}}$

Substituting $\overline{\mathrm{r}} / \overline{\mathrm{r}}_{0}$ from Eq. (16) into Eqs. (9) and $(10)$, we get:

$$
\begin{aligned}
& f^{\prime \prime \prime}-\frac{y^{*}}{\eta} f^{\prime \prime}+\frac{y^{*}}{()^{2}} f^{\prime}+\frac{1}{(1)} x \\
& \times\left\{\left(R+\frac{4}{5}\right) f f^{\prime \prime}-\left[\left(R+\frac{3}{5}\right)-\frac{R}{(T)}\right]\left(f^{\prime}\right)^{2}\right\} \\
& -\frac{\gamma^{*}}{()^{2}} f^{\prime}\left[\left(R+\frac{4}{5}\right) f-\frac{1}{5} \eta f^{\prime}\right]+() g \\
& =\xi\left\{\frac{f^{\prime}}{(I)} \frac{\partial f^{\prime}}{\partial \xi}-\frac{() f^{\prime \prime}-\gamma^{*} f^{\prime}}{()^{2}} \frac{\partial f}{\partial \xi}\right\} \\
& g^{\prime \prime}+\frac{\gamma^{*}}{\left(\zeta^{\prime}\right.} g^{\prime}+\left(R+\frac{4}{5}\right) \frac{P r}{\Gamma} f^{\prime}-\frac{1}{5} \stackrel{P r}{\nearrow} f^{\prime} g \\
& =\xi \frac{\operatorname{Pr}}{(T}\left\{f^{\prime} \frac{\partial g}{\partial \xi}-g^{\prime} \frac{\partial f}{\partial \xi}\right\}
\end{aligned}
$$

subject to the boundary conditions:

$\eta=0: f(\xi, 0)=f^{\prime}(\xi, 0)=0 ; g^{\prime}(\xi, 0)=-1$

$\eta=\propto: f^{\prime}(\xi, \propto)=0 ; g(\xi, \propto)=0$ 
where the notation "( )" in Eqs. (18) and (19) represents the two terms on the right-hand side of Eq. (16) and

$$
\gamma^{*}=\gamma \frac{\xi^{1 / 5}}{1+\xi}
$$

\section{Numerical Solutions}

To solve Eqs. (18) and (19), they are first written as a first-order system. The derivatives are then approximated by centered-difference gradients and averages centered at the midpoints of the net rectangles defined by:

$\xi_{0}=0, \xi_{n}=\xi_{n-1}+k_{n}, n=1,2, \ldots, N$

$\eta_{0}=0, \eta_{j}=\eta_{j-1}+h_{j}, j=1,2, \ldots, J$

$\eta_{\mathrm{J}}=\eta_{\propto}$

as shown in Figure 2. A non-uniform grid $h_{j}$ defined by

$h_{j}=K h_{j-1}$

where the ratio of adjacent intervals, $K$, is a constant. The distance from the surface to the $j$ th station is then given by:

$\eta_{j}=h_{j} \frac{K^{j}-1}{K-1}, j=1,2, \ldots, J$

The $\xi$-direction grid $k_{n}$ is arbitrary. Linearization is achieved by the method of quasilinearization and the resulting system of algebraic equations are then solved by an efficient block-tridiagonal factorization technique. Details of the method of solution are identical to the one used in reference 11 and are therefore omitted here.

In engineering applications, it is the surface temperature $T_{w}(x)$ that is of interest for the case in which the wall heat flux is specified. From the definitions of Eqs. (4) and (7),

$$
\begin{aligned}
& {\left[T_{w}(x)-T_{\propto}\right]_{T V C}=} \\
& =\frac{\left(q_{0} x_{0} / k\right) \xi^{1 / 5}}{\left\{\frac{g_{e} \beta \cos \alpha\left(q_{0} x_{0} / k\right) x_{0}^{3}}{\nu^{2}}\right\}^{1 / 5}}\left[g(\xi, 0]_{T V C}\right.
\end{aligned}
$$

where the subscript "TVC" means the effect of TVC is included. If the cone angle $\alpha$ is large, the effect of TVC is negligible and Eqs. (9) and (10) become:

$$
\begin{array}{r}
f^{\prime \prime \prime}+\left(R+\frac{4}{5}\right) f f^{\prime \prime}-\frac{3}{5}\left(f^{\prime}\right)^{2}+g \\
=\xi\left(f^{\prime} \frac{\partial f^{\prime}}{\partial \xi}-f^{\prime \prime} \frac{\partial f}{\partial \xi}\right) \\
g^{\prime \prime \prime}+\left(R+\frac{4}{5}\right) \operatorname{Prf} g^{\prime}-\frac{1}{5} \operatorname{Prf} g \\
=\xi \operatorname{Pr}\left(f^{\prime} \frac{\partial g}{\partial \xi}-g^{\prime} \frac{\partial f}{\partial \xi}\right)
\end{array}
$$

which are also non-similar. The expression for the wall temperature is given by:

$$
\begin{aligned}
& {\left[\mathrm{T}_{\mathrm{w}}(\mathrm{x})-\mathrm{T}_{\left.\alpha{ }^{\prime}\right]_{\mathrm{NO}-\mathrm{TVC}}}=\right.} \\
& =\frac{\left(\mathrm{q}_{0} \mathrm{x}_{0} / \mathrm{k}\right) \xi^{1 / 5}}{\left\{\frac{\mathrm{g}_{\mathrm{e}} \beta \operatorname{Cos} \alpha\left(\mathrm{q}_{0} \mathrm{x}_{0} / \mathrm{k}\right) \mathrm{x}_{0}^{3}}{\nu^{2}}\right\}^{1 / 5}[\mathrm{~g}(\xi, 0)]_{\mathrm{NO}-\mathrm{TVC}}}
\end{aligned}
$$

The effect of TVC as a result of slenderness can therefore be characterized by the following ratio:

$R_{\text {TVC }}=\frac{\left[T_{W}(x)-T_{\propto}\right]_{T V C}}{\left[T_{W}(x)-T_{\propto}\right]_{N O-T V C}}=\frac{[g(\xi, 0)]_{T V C}}{[g(\xi, 0)]_{N O-T V C}}$.

If the TVC effect is negligible, the ratio $\mathrm{R}_{\text {TVC }}$ will be approximately 1 . The ratio $R_{\text {TVC }}$ is greater or smaller than 1 depending on whether the wall temperature $\mathrm{T}_{\mathrm{W}}$ is increased or decreased, respectively, as a result of TVC.

To calculate the ratio $R_{\text {TVC }}$, Eqs. (25) and (26) are first solved, from which we get $[\mathrm{g}(\xi, 0)]_{\mathrm{NO}-T V C}$ as a function of $\xi$. Then (18) and (19) are solved, from which we obtain $[g(\xi, 0)]_{\text {TVC }}$ as a function of $\xi$. The ratio of the two sets of solutions then give the ratio $R_{\text {TVC }}$ as a function of $\xi$. Table 1 gives the ratio $R_{\text {TVC }}$ as a function of $\xi$ for $\operatorname{Pr}=1.00$ and for a few values of TVC parameter, $\gamma$, namely $0.25,0.5,0.75$ and 1.00 , respectively. The following conclusions are drawn:

1. For all the cases considered, the effect of TVC is to decrease the wall temperature $T_{w}(x)$ for a given value of the TVC parameter $\gamma$. The decrease is seen to 
Table 2. $R_{\text {TV }}$ for various Prandtl numbers (for $\gamma=0.75$ )

\begin{tabular}{rllll}
\hline \multicolumn{5}{c}{$\mathrm{R}_{\text {TVC }}$} \\
$\xi$ & Pr=0.1 & $\operatorname{Pr}=1.0$ & $\operatorname{Pr}=10$ & $\operatorname{Pr}=100$ \\
\cline { 2 - 5 } & & & & \\
\hline 0.00 & 1.0000 & $\mathbf{1 . 0 0 0 0}$ & $\mathbf{1 . 0 0 0 0}$ & 1.0000 \\
0.25 & 0.8293 & 0.8821 & 0.9151 & 0.9447 \\
0.75 & 0.6801 & 0.7989 & 0.8703 & 0.9180 \\
1.75 & 0.7082 & 0.8270 & 0.8948 & 0.9343 \\
3.75 & 0.7734 & 0.8676 & 0.9205 & 0.9513 \\
7.75 & 0.8303 & 0.9067 & 0.9473 & 0.9684 \\
15.75 & 0.8873 & 0.9403 & 0.9666 & 0.9804 \\
31.75 & 0.9273 & 0.9624 & 0.9800 & 0.9884 \\
63.75 & 0.9553 & 0.9781 & 0.9882 & 0.9931 \\
127.75 & 0.9729 & 0.9866 & 0.9930 & 0.9961 \\
\hline
\end{tabular}

reach $25 \%$ for the largest value of the TVC parameter $(y=1)$ presented in Table 1 .

2. The ratio $R_{\text {TVC }}$ first decreases with $\xi$, reaches a minimum at a certain location and then increases with $\xi$. Ultimately, $R_{\text {TVC }}$ will approach to 1 at very large value of $\xi$ which means the solutions will approach to the similarity solution of Eqs. (12) and (13). This is physically reasonable since, as $\xi$ increases, the boundary layer thickness becomes small as compared with the radius of the cone, $r_{0}$, and as a result the TVC effect becomes less important.

3 . Larger values of the TVC parameter $\gamma$ corresponds to more profound TVC effect. From the definition of $\gamma$, a large $\gamma$ means either a smaller cone angle $\alpha$ or a smaller $x_{0}$. In both cases, the boundary layer thickness becomes closer to the cone radius $r_{0}$ and an increase in the TVC effect results. Since an increase in the wall heat flux, $q_{0}$, results in a decrease in the value of the TVC parameter $\gamma$, the TVC effect is seen to be inversely proportional to the wall heat flux (raised to the power of $1 / 5$ ).

4. The effect of TVC is different for different values of Prandtl numbers. As an illustration, the wall temperatures are tabulated in Table 2 for one value of the TVC parameter and for a few values of Prandtl numbers. It is seen that the effect of TVC is more pronounced for smaller Prandtl numbers.

Similar to reference [8], we conclude the paper by showing how the solution for the frustrum of a cone as presented above can be used approximately for a full cone. Consider, for example, the problem of natural convection of air at $80^{\circ} \mathrm{F}$ over the frustrum of a cone $\left(\mathrm{L}=1 \mathrm{ft}, \mathrm{x}_{0}=2\right.$ in. and $\left.\alpha=5^{\circ}\right)$ with constant heat flux of $1000 \mathrm{Btu} / \mathrm{hr}-\mathrm{ft}^{2}$. For this case, the TVC parameter $\gamma$ is found to be approximately 0.38. If we decrease $x_{0}$ from 2 in. to 0.5 in., the corresponding value of $\gamma$ will be 1.15. For such a small value of $x_{0}$ (Fig. 1$)$, the solution for the frustrum of a cone becomes a good approximation of the boundary layer flow over a full cone with $L=12.5 \mathrm{in}$., esspecially in view of the fact that the boundary layer equations no longer apply near the tip of a full cone. This approximation is of significance since, from the mathematical point of view, a zero value of $\mathrm{x}_{0}$ will give rise to a mathematical singularity in the transverse curvature factor $\overline{\mathrm{r}} / \overline{\mathrm{r}}_{0}$ in the differential equation, Eqs. (9) and (10). It should be noted that the same difficulty was by-passed in a similar manner in the analysis of the heat transfer over a slender cone by Kuiken [7]. In his work, Kuiken used in effect the inverse of the distance measured from the tip along the cone surface as the flow-direction co-

Table 1. Selected solutions of $R_{T V C}$ for $\operatorname{Pr}=1.00$

\begin{tabular}{rllllll}
\hline \multicolumn{7}{c}{$R_{\text {TVC }}$} \\
\cline { 3 - 6 }$\xi$ & {$[g(\xi, 0)]$ NO-TVC } & $\gamma=0.25$ & $\gamma=0.50$ & $\gamma=0.75$ & $\gamma=1.00$ \\
\hline 0.00 & 1.8729 & 1.0000 & 1.0000 & 1.0000 & 1.0000 \\
0.25 & 1.8282 & 0.9547 & 0.9157 & 0.8821 & 0.8467 \\
0.75 & 1.7841 & 0.9199 & 0.8542 & 0.7989 & 0.7493 \\
1.75 & 1.7325 & 0.9307 & 0.8743 & 0.8270 & 0.7871 \\
3.75 & 1.6930 & 0.9494 & 0.9058 & 0.8676 & 0.8334 \\
7.75 & 1.6649 & 0.9653 & 0.9345 & 0.9067 & 0.8817 \\
15.75 & 1.6498 & 0.9787 & 0.9589 & 0.9403 & 0.9227 \\
31.75 & 1.6406 & 0.9868 & 0.9743 & 0.9624 & 0.9511 \\
63.75 & 1.6368 & 0.9925 & 0.9852 & 0.9781 & 0.9710 \\
127.75 & 1.6339 & 0.9955 & 0.9909 & 0.9866 & 0.9823 \\
$\propto$ & 1.6327 & 1.0000 & 1.0000 & 1.0000 & 1.0000 \\
\hline
\end{tabular}


ordinate ( $\xi$ ). As a result, his solutions started from the downstream side and integrated step-by-step in the opposite direction of the flow. Therefore, the tip of the cone in Kuiken's analysis corresponds to $\xi$ equals to infinity. Since his integration stops at a finite value of $\xi$, the solution never reaches the tip of the cone. By this way, singularity at the tip of the cone was avoided.

\section{References}

1. Merk, H.J.; Prins, J.A.: Thermal Convection in Laminar Boundary Layer. Appl. Sci. Res. 4 A (1953) 11-24, 195-206

2. Hering, R.G.; Grosh, R.J.: Laminar Free Convection from a Non-Isothermal Cone. Int' $1 \mathrm{~J}$. of Heat and Mass Transfer 5 (1962) 1059-1067

3. Hering, R.G.: Laminar Free Convection From a Non-Isothermal Cone at Low Prandtl Numbers. Int. J. of Heat and Mass Transfer 8 (1965) 1333-1337

4. Sparrow, E.M.; Guinle, L.D.F.: Deviation From Classical Free Convection Boundary Layer Theory at Low Prandtl Numbers. Int. J . of Heat and Mass Transfer 11 (1968) 1403-1415

5. Roy, S.: Free Convection From a Vertical Cone at High Prandtl Numbers. J. of Heat Transfer, Trans. ASME 96 (1974) 115-117

6. Lin, F.N.: Laminar Free Convection From a Vertical Cone With Uniform Surface Heat Flux. Letters in Heat and Mass Transfer 3 (1976) $49-58$
7. Kuiken, H.K.: Axisymmetric Free Convection Boundary Layer Flow Past Slender Bodies. Int. $\mathrm{J}$. of Heat and Mass Transfer 11 (1968) 1141-1153

8. Na, T.Y.; Chiou, J.P.: Laminar Natural Convection Over a Slender Vertical Frustrum of a Cone. (to appear in Wärme- und Stoffübertragung 1979)

9. Cebeci, T.; Qasim, J.; Na, T.Y.: Free Convective Heat Transfer From Slender Cylinders Subject to Uniform Wall Heat Flux. Letters in Heat and Mass Transfer 1, No. 2 (1974) 159-162

10. Cebeci, T. : Laminar Free Convection Heat Transfer From the Outer Surface of a Vertical Slender Circular Cylinder. Proc. of the 5th International Heat Transfer Conference 3, No. NCl. 4 (1974) 15-19

11. Na, T.Y.: N umerical Solution of Natural Convection Flow Past a Non-Isothermal Vertical Flat Plate. Appl. Sci. Res. 33 (1978) 519-543

Prof. T.Y. Na

University of Michigan-Dearborn

Dearborn, Michigan, 48128, USA

Prof. Dr. J.P. Chiou

University of Detroit

Detroit, Michigan, 48221, USA

Received March 1, 1979 